\title{
Fluocinolone acetonide and its potential in the treatment of chronic diabetic macular edema
}

\section{Christos Haritoglou \\ Aljoscha S Neubauer Marcus Kernt}

Department of Ophthalmology, Ludwig-Maximilians-University,

Munich, Germany
Correspondence: Christos Haritoglou Ludwig-Maximilians-University, Department of Ophthalmology, Klinikum der Universität München Campus Innenstadt, Mathildenstrasse 8, Munich D-80336, Germany

Tel +4989516038II

Fax +498951605160

Email christos.haritoglou@med.unimuenchen.de
This article was published in the following Dove Press journal:

Clinical Ophthalmology

7 March 2013

Number of times this article has been viewed

\begin{abstract}
Diabetic macular edema (DME) is a potentially sight-threatening disease that predominantly affects patients with type 2 diabetes. The pathogenesis is complex, with many contributing factors involved. In addition to overexpression of vascular endothelial growth factor in the diabetic eye, there is an inflammatory pathway that contributes to the breakdown of the blood-retina barrier and nonperfusion. In addition to vascular endothelial growth factor inhibitors, clinical and experimental investigations underline the great potential of steroids in the treatment of DME. Fluocinolone acetonide is currently the only corticosteroid approved for the treatment of DME in Europe. It is manufactured as an intravitreal insert, releasing fluocinolone acetonide at a rate of $0.2 \mu \mathrm{g}$ per day. Phase III clinical studies have demonstrated that the beneficial effect of the fluocinolone acetonide insert lasts up to 3 years. Improvement in visual acuity was especially remarkable in patients with a prolonged duration of DME of at least 3 years at the initiation of therapy. Cataract formation occurs in nearly all phakic eyes treated, and needs to be considered when the indication for treatment is made. Given the efficacy versus potential complications of the insert, fluocinolone acetonide represents a promising second-line treatment option in patients with DME. Fluocinolone appears to be especially beneficial for patients whose options for visual recovery have seemed limited up until now.
\end{abstract}

Keywords: diabetic macular edema, fluocinolone acetonide

\section{Introduction}

Diabetic retinopathy is a sight-threatening disease and represents the most frequent cause of blindness among people of working age in industrialized Western nations. ${ }^{1-3}$ After a duration of diabetes mellitus of 5 years, 29\% of type 2 diabetics suffer from diabetic retinopathy, $78 \%$ of patients are affected after 15 years, and 16\% develop the proliferative stage of the disease. ${ }^{2}$ In type 1 diabetics, the numbers are reported to be very similar, with $17 \%$ of type 1 diabetics presenting with proliferative diabetic retinopathy after 5 years, $98 \%$ after 15 years, and $67 \%$ after 35 years of suffering from the disease. ${ }^{2,3}$ While the development of diabetic macular edema (DME) is the major cause of visual impairment in type 2 diabetics, proliferative diabetic retinopathy is predominantly seen in type 1 diabetics. Approximately $90 \%$ of type 1 diabetic patients become legally blind because of proliferative diabetic retinopathy and/or the development of macular edema, despite several effective treatment options, such as laser treatment and vitreoretinal surgery being available. ${ }^{3}$ In addition to timely and tight glycemic control to achieve near-normal glycosylated hemoglobin levels and blood pressure below 130/80 $\mathrm{mmHg}$, prevention of visual loss depends on timely detection of the sight-threatening complications of diabetic retinopathy, such as macular 
edema, and immediate initiation of adequate therapy. Until recently, laser treatment was the only evidence-based treatment option available to preserve vision in patients with DME. ${ }^{4-6}$ However, laser treatment is not always beneficial, especially in diffuse DME involving the fovea. With regard to the variable and sometimes unsatisfactory functional results following laser photocoagulation, new pharmacological strategies have been proposed in order to improve the visual outcome, including use of vascular endothelial growth factor inhibitors and steroids. ${ }^{7-13}$ These pharmacological monotherapies are based on our growing understanding of the complex and multifactorial pathogenesis of DME. At present, two pharmacological treatments are approved in many European countries for the treatment of DME, ie, intravitreal injection of the vascular endothelial growth factor (VEGF) inhibitor, ranibizumab (Lucentis ${ }^{\circledR}$, Novartis, Basel, Switzerland), as a first-line treatment and the fluocinolone acetonide-loaded insert (Iluvien ${ }^{\circledR}$, Alimera Sciences Inc, Alpharetta, GA) as a second-line treatment in refractory cases of DME. The present review discusses predominantly the use of steroids for the treatment of DME and introduces the rationale for fluocinolone acetonide as a therapeutic agent for this condition.

\section{Pathophysiology of DME}

The common pathway for the pathogenesis of DME is breakdown of the blood-retina barrier, resulting in an abnormal inflow of fluid in the neurosensory retina. Vascular leakage and retinal nonperfusion are mediated by numerous growth factors. ${ }^{14}$ However, according to our current understanding of the pathogenesis of macular edema, the formation of edema and leakage result not only from an overexpression of VEGF-A, but also from inflammatory responses. ${ }^{15}$

In the multifactorial pathogenesis of DME, sustained hyperglycemia upregulates several vasoactive factors, including VEGF, protein kinase C, and angiotensin II. All these factors are interrelated in a very complex fashion, and contribute to development of the structural and functional changes seen in diabetic retinopathy. ${ }^{15-20}$ Upregulation of VEGF leads to a breakdown of the blood-retinal-barrier and increased vascular permeability, resulting in leakage of fluid and plasma constituents, such as lipoproteins, into the retina. ${ }^{20-22} \mathrm{VEGF}$ is now an important target in the treatment of DME using VEGF inhibitors such as ranibizumab or bevacizumab. However, there are many other factors being upregulated in the vitreous cavity in the pathogenesis of DME which also affect the blood-retina barrier, ie, high glucose levels in endothelial cells are associated with mitochondrial overproduction of reactive oxygen species, which inactivate glyceraldehyde-3-phosphate dehydrogenase and also contribute to vascular endothelial damage..$^{20,23}$

Furthermore, it is not only the impaired blood-retina barrier that contributes to the pathogenesis of macular edema, but also dysfunction of Müller cells, which are the principal glial cells of the retina. Müller cells are important structures for fluid clearance from the retina and help to maintain the homeostasis of the retinal extracellular space. Under normal conditions, Müller cells facilitate transcellular water transport via ion (Kir4.1) and water channels such as aquaporin 4. In the diabetic retina, Müller cells downregulate expression of Kir4.1 channels, leading to intracellular accumulation of potassium ions and increased intracellular osmotic pressure, finally resulting in intracellular edema facilitated by aquaporin 4 channels. ${ }^{24}$ Animal models have shown that corticosteroids are able to regulate aquaporin 4 expression and to stimulate efflux of potassium ions associated with water transport out of the cell, which finally leads to reduction of the intracellular edema. ${ }^{24}$

In addition, it has been shown in experimental animal models of the diabetic retina that leukocytes accumulate in the diabetic retina mediated by increased expression of specific adhesion molecules, such as intercellular adhesion molecule-1, and may trigger relevant mechanisms in the pathogenesis of DME, such as retinal vascular leakage and nonperfusion..$^{25,26}$ Intravitreally applied corticosteroids have been shown to be able to attenuate leukostasis and the associated breakdown of the blood-retina barrier in DME, as seen by a downregulation of mRNA expression of intercellular adhesion molecule- 1 and its protein by $70.0 \%(P<0.0001)$ and $56.4 \%(P=0.0003)$, respectively, in response to treatment with dexamethasone. ${ }^{25}$

Against this background, it seems reasonable not to target VEGF alone, but also to block the inflammatory pathways. Corticosteroids are not only able to attenuate the effects driven by overexpression of VEGF-A, but also reduce inflammation. They represent a class of drugs that, among other effects, counteract these mechanisms by interrupting intercellular adhesion molecule-1, interleukin-6, and VEGF-A pathways, reducing aquaporin 4 , decreasing paracellular permeability and water and solute flux, and increasing tight junction integrity and transepithelial resistance. ${ }^{14}$

\section{Profile of fluorinated glucocorticoids}

Corticosteroids are derived from the adrenal cortex and include both glucocorticoids and mineralocorticoids. One can differentiate natural glucocorticoids, such as 
cortisol, cortisone, and corticosterone, from the synthetic glucocorticoids, prednisolone and fluocinolone acetonide. In contrast with the natural glucocorticoids and prednisolone, triamcinolone acetonide, dexamethasone, and fluocinolone acetonide are devoid of mineralocorticoid receptor activity and are among the most potent as well as selective glucocorticoid receptor agonists. Because of their chemical structures, fluocinolone acetonide, triamcinolone acetonide, and dexamethasone are referred to as fluorinated glucocorticoids (Figure 1) but have some molecular differences, ie, fluocinolone acetonide and triamcinolone acetonide have a stable C16-C17 acetonide group, whereas dexamethasone has a methyl group on the $\mathrm{C} 16$ position and a hydroxyl group on the $\mathrm{C} 17$ position. Fluocinolone acetonide is further differentiated from triamcinolone acetonide and dexamethasone by a fluorine on the C6 position. ${ }^{27}$

Their high potency and selectivity allow for a smaller initial drug load and a lower release rate to achieve high enough vitreal and retinal concentrations and provide therapeutic efficacy in the macular region. ${ }^{27}$ Today, these three glucocorticoids represent those which are most frequently used for intraocular application. The vitreous elimination half-life of the solubilized fraction of fluocinolone acetonide, triamcinolone acetonide, and dexamethasone is similar and very short, ranging from 2 to 3 hours. ${ }^{27}$ An extended duration of action may be achieved via dissolution of crystals (triamcinolone acetonide, Kenalog ${ }^{\circledR}$, Bristol-Myers Squibb, New York, NY, USA) or by drug-release systems for fluocinolone acetonide and dexamethasone, which help to provide an even more prolonged pharmacological effect with these relatively more highly water-soluble steroids. ${ }^{27}$ For fluocinolone acetonide, this extended pharmacological effect within the eye can be established by nondegradable controlledrelease systems, which may be injected (Iluvien) or surgically implanted (Retisert ${ }^{\circledR}$, Bausch and Lomb, Irvine, CA, USA) into the vitreous cavity via the pars plana. A degradable

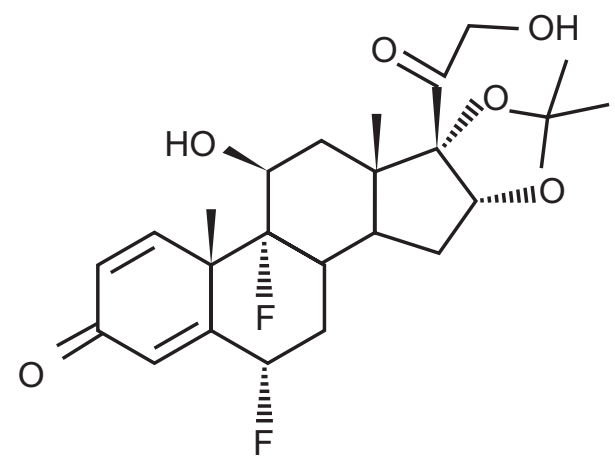

Figure I Molecular formula for fluocinolone acetonide. extended-release injectable drug implant is also available for dexamethasone (Ozurdex ${ }^{\circledR}$, Allergan, Irvine, CA, USA). ${ }^{28} \mathrm{At}$ present, fluocinolone acetonide as an injectable intravitreal insert (Iluvien) is the only steroid approved for the treatment of chronic refractory DME in Europe.

\section{Fluocinolone acetonide in the treatment of DME}

Based on the results of the Early Treatment of Diabetic Retinopathy Study (ETDRS), laser photocoagulation has typically been considered the gold standard for the treatment of focal DME. ${ }^{29}$ However, although the distinction of different types of DME was recently questioned, it is also known that patients with so-called diffuse macular edema or refractory DME in particular do not respond to laser treatment as effectively. ${ }^{30,31}$ Therefore, other therapeutic agents, such as intravitreally applied corticosteroids, have been sought to treat eyes with DME. There are numerous studies describing improvement in visual acuity and decreased retinal thickness, as measured by optical coherence tomography, using different steroids, such as triamcinolone acetonide suspensions $^{32,33}$ and an intravitreal dexamethasone drug delivery system (Ozurdex). ${ }^{32-35}$ The observed treatment effects could be maintained for up to 6 months using variable triamcinolone acetonide doses of 1-20 mg and for approximately 4 months using the dexamethasone implant. ${ }^{34,36,37}$ However, neither agent is currently approved for the treatment of DME.

Fluocinolone acetonide is approved in many European countries for the treatment of DME as the $190 \mu \mathrm{g}$ intravitreal insert which can be injected into the eye. The slightly brownish insert is applied intravitreally through the 25-gauge needle of a single use applicator and releases $0.2 \mu \mathrm{g}$ per day.

Before approval, the intravitreal insert was investigated in several trials. The prospective, randomized, interventional, multicenter FAMOUS (Fluocinolone Acetonide in Human Aqueous) study, published in 2010, ${ }^{38,39}$ included 37 patients with DME persisting after at least one previous laser photocoagulation (focal/grid) who were randomized $1: 1$ to receive an intravitreal $0.2 \mu \mathrm{g} /$ day or $0.5 \mu \mathrm{g} /$ day insert. Aqueous levels of fluocinolone acetonide after 12 months were the primary endpoint and change in visual acuity compared with baseline at 12 months was the secondary endpoint. The study revealed excellent sustained intraocular drug release over the study period, with a peak of $3.8 \mathrm{ng} / \mathrm{mL}$ at one week and one month, respectively, after administration of the $0.5 \mu \mathrm{g}$ /day insert, and $3.4 \mathrm{ng} / \mathrm{mL}$ and $2.7 \mathrm{ng} / \mathrm{mL}$ one week and one month, respectively, after administration of the $0.2 \mu \mathrm{g} /$ day insert. ${ }^{38}$ Both dosages provided stable long-term release of the drug, with comparable peak levels in the aqueous of above $2 \mathrm{ng} / \mathrm{mL}$ 
for approximately 3 months, followed by steady-state levels of $1.0-0.5 \mathrm{ng} / \mathrm{mL}$ through 36 months for the low-dose insert versus levels of $1.5-1.1 \mathrm{ng} / \mathrm{mL}$ through 24 months for the high-dose insert. ${ }^{39}$ An improvement in visual acuity of 7.5, 6.9, and 5.7 letters at months 3,6 , and 12 for the $0.5 \mu \mathrm{g} /$ day insert and 5.1, 2.7, and 1.3 letters at months for the $0.2 \mu \mathrm{g}$ /day insert was seen. ${ }^{38} \mathrm{~A}$ mild increase in mean intraocular pressure was observed after administration of the $0.5 \mu \mathrm{g} /$ day insert, but not after administration of the $0.2 \mu \mathrm{g} /$ day insert. ${ }^{38}$ However, it became apparent that there was a dose effect for steroid-induced ocular hypertension, with aqueous levels of fluocinolone acetonide $>1 \mathrm{ng} / \mathrm{mL}$ moderately increasing the risk of glaucoma in susceptible patients. ${ }^{39}$

The long-term clinical efficacy of the $0.2 \mu \mathrm{g}$ /day versus the $0.5 \mu \mathrm{g}$ /day fluocinolone acetonide insert was assessed in the FAME (Fluocinolone Acetonide in Diabetic Macular Edema) study, ${ }^{40}$ which was designed as two parallel, prospective, randomized, sham injection-controlled, double-masked, multicenter clinical trials. The study included 956 patients with persistent DME despite at least one previous laser photocoagulation. Participants were randomized 1:2:2 to receive a sham injection, the low-dose insert, or the highdose insert. The percentage of patients with an improvement of $\geq 15$ ETDRS letters from baseline best-corrected visual acuity after 2 years of follow-up was the primary outcome measure of this study. Secondary outcomes included other parameters of visual function and foveal thickness.

The study demonstrated a significant improvement of $\geq 15$ letters compared with baseline in $28.7 \%$ and $28.6 \%$ of the low-dose and high-dose insert groups, respectively, compared with $16.2 \%$ in the sham group. This benefit was observed at 3 weeks and at all subsequent time points thereafter. Between baseline and 2 years, patients improved by 4.4 letters in the low-dose group and 5.4 letters in the highdose group, compared with 1.7 in the sham group. Foveal thickness was significantly more improved in treated patients compared with the sham group for the entire duration of follow-up. Lens opacification requiring cataract extraction and intraocular lens implantation was more frequent in the treated group. Patients who were phakic at baseline and at the end of follow-up at 24 months experienced an improvement in visual acuity during the early phase of the trial, but then deteriorated significantly and had lower visual acuity than the sham group. ${ }^{40}$ Cataract extraction was performed in $41.1 \%$ of patients on the low-dose insert group, $50.9 \%$ on the high-dose insert group, and $7 \%$ of the sham group, which constituted $74.9 \%$ of all phakic subjects at baseline in the low-dose insert group and $84.5 \%$ in the high-dose insert group compared with $23.1 \%$ in the sham group. The visual benefit for patients who underwent cataract surgery was similar to that in subjects who were already pseudophakic at baseline. Increased intraocular pressure was seen in 3\% of both treatment groups. ${ }^{40}$ When increased pressure was prolonged or could not be controlled by topical treatment, other intraocular pressure-lowering procedures were performed, such as incisional glaucoma surgery in $8.1 \%$ of the high-dose insert group, 3.7\% in the low-dose insert group, and $0.5 \%$ in the sham group. ${ }^{40}$ Retreatment was required in $20 \%$ of patients in all groups during follow-up, but patients from the active treatment groups were less likely to receive additional treatment for DME. All in all, the FAME trial clearly showed a significant functional benefit for patients treated with fluocinolone acetonide $0.2 \mu \mathrm{g} /$ day or $0.5 \mu \mathrm{g} /$ day over a follow-up period of 24 months, with a superior riskto-benefit ratio for the lower-dose insert. For a summary, please refer to Table 1 .

A preplanned analysis at 36 months was conducted to assess the efficacy of Iluvien as a function of median DME duration at baseline, and demonstrated that the percentage of patients who had gained at least 15 ETDRS letters was $28.7 \%$ and $27.8 \%$ for patients treated with the low-dose insert or high-dose insert, respectively, compared with $18.9 \%(P=0.018)$ in the sham group. Values were slightly higher when considering only those patients still in the trial at month 36 , ie, $33.0 \%$ in the low-dose insert group, $31.9 \%$ in the high-dose insert group, and $21.4 \%$ in the sham group $(P=0.030) .{ }^{41}$ Of note, when looking at patients with a duration of DME of more than 3 years at baseline, the percentage of patients who gained $\geq 15$ ETDRS letters was doubled comparing the low-dose group with the sham group (34\% versus $13.4 \%, P<0.001)$. Cataract development in initially phakic patients was seen in $81.7 \%$ of the low-dose insert group, $88.7 \%$ of the high-dose insert group, and 5.4\% of the sham group, but again their visual benefit after cataract surgery (performed in $80 \%, 87.2 \%$, and $27.3 \%$, respectively) was similar to that in pseudophakic patients. ${ }^{41}$ The incidence of incisional glaucoma surgery at month 36 was $4.8 \%$ in the low-dose insert group and $8.1 \%$ in the high-dose insert group. ${ }^{41}$ In summary, this study underlined that the treatment benefit is maintained over a period of 3 years.

Another prospective, multicenter clinical trial investigated 3-year efficacy and 4-year safety in 196 eyes with refractory DME. ${ }^{42}$ In this study, patients received a fluocinolone acetonide implant (Retisert ${ }^{\circledR}$, Bausch and Lomb) which is surgically implanted through a pars plana incision and designed to release fluocinolone acetonide at an initial rate 
Table I Clinical characteristics of patients according to treatment allocation

\begin{tabular}{|c|c|c|c|c|}
\hline Baseline & $\begin{array}{l}\text { Sham } \\
n=185\end{array}$ & $\begin{array}{l}0.2 \mu \mathrm{g} / \text { day } \\
\mathrm{n}=375\end{array}$ & $\begin{array}{l}0.5 \mu \mathrm{g} / \text { day } \\
\mathrm{n}=393\end{array}$ & $\begin{array}{l}\text { Total } \\
n=953\end{array}$ \\
\hline Time since diagnosis of DME in years, mean \pm SD & $3.9 \pm 3.78$ & $3.6 \pm 2.92$ & $3.5 \pm 2.60$ & $3.6 \pm 2.99$ \\
\hline Phakic eyes at entry, n (\%) & $|2|(65.4)$ & $235(62.7)$ & $265(67.4)$ & $621(65.2)$ \\
\hline Baseline IOP, mean \pm SD & $15 \pm 3.07$ & $15.2 \pm 2.94$ & $15.2 \pm 2.87$ & $15.2 \pm 2.94$ \\
\hline Baseline BCVA in ETDRS letters, mean $\pm S D$ & $54.7 \pm 11.27$ & $53.3 \pm 12.69$ & $52.9 \pm 12.21$ & $53.4 \pm 12.23$ \\
\hline Center point thickness $\mu \mathrm{m}$, mean $\pm \mathrm{SD}$ & $451.3 \pm 151.97$ & $460.8 \pm 160.00$ & $485.1 \pm 173.78$ & $469.0 \pm 164.78$ \\
\hline \multicolumn{5}{|l|}{ Follow-up 24 months } \\
\hline Gain $\geq$ letters (\%) & 16 & 28 & 28 & \\
\hline Mean improvement in letters & 1.7 & 4.4 & 5.4 & \\
\hline Center point thickness $\leq 250 \mu \mathrm{m}(\%)$ & 40 & 51 & 47 & \\
\hline Cataract surgery (\%) & 7 & 41.1 & 50.9 & \\
\hline Initially phakic patients, \% & 23.1 & 74.9 & 84.5 & \\
\hline Laser trabeculoplasty (\%) & 0 & 0.8 & 2.3 & \\
\hline Incisional glaucoma surgery (\%) & 0.5 & 3.7 & 8.1 & \\
\hline
\end{tabular}

Abbreviations: BCVA, best-corrected visual acuity; DME, diabetic macular edema; ETDRS, Early Treatment Diabetic Retinopathy Study; IOP, intraocular pressure; SD, standard deviation.

of approximately $0.6 \mu \mathrm{g} / \mathrm{day}$, decreasing over the first month to a steady rate of $0.3-0.4 \mu \mathrm{g} /$ day for a duration of approximately 30 months and currently approved for patients with uveitis. Patients were randomized 2:1 and compared with standard of care, ie, laser photocoagulation or observation. The primary efficacy outcome was an improvement in visual acuity of $\geq 15$ letters at 6 months, while secondary outcomes included resolution of macular retinal thickening and change in diabetic retinopathy severity score. The authors observed an overall improvement in visual acuity of at least three lines in $16.8 \%$ of treated eyes at 6 months $(P=0.0012), 16.4 \%$ at one year $(P=0.1191), 31.8 \%$ at 2 years $(P=0.0016)$, and $31.1 \%$ at 3 years $(P=0.1566)$. After treatment, the number of eyes with flat maculae was higher, as was the rate of improvement in visual acuity, along with a lower rate of decline in diabetic retinopathy severity score. An increase in intraocular pressure to over $30 \mathrm{mmHg}$ was recorded in $61.4 \%$ of implanted eyes versus $5.8 \%$ in the control group at any time, and $33.8 \%$ required surgery for ocular hypertension by 4 years. By 4 years, $91 \%$ of implanted phakic eyes had undergone cataract extraction compared with $20 \%$ in the standard of care group. ${ }^{42}$

\section{Summary of current treatment options}

Fluocinolone acetonide, which is to date approved in European countries as a $0.2 \mu \mathrm{g} /$ day drug-release insert for the treatment of macular edema, provides significant and longlasting improvement of function and reduction in retinal thickness. As clinical studies have shown, the insert is more effective in chronic cases of DME compared with more recent onset disease. With regard to ocular complications, one needs to take into account that cataract surgery will become necessary in nearly all patients who are phakic at the initiation of treatment. An increase in intraocular pressure may occur, but surgical intervention becomes necessary only in a limited number of patients. Therefore, fluocinolone acetonide may represent an effective second-line treatment option for patients with chronic, refractory, diffuse DME, which to date comprise a group of patients with limited prospects for visual recovery (Figures 2 and 3). At present, as a first-line treatment, laser photocoagulation remains relevant for focal vasogenic DME not involving the fovea, and may help to maintain good visual acuity. Anti-VEGF treatment seems indicated in new focal DME involving the

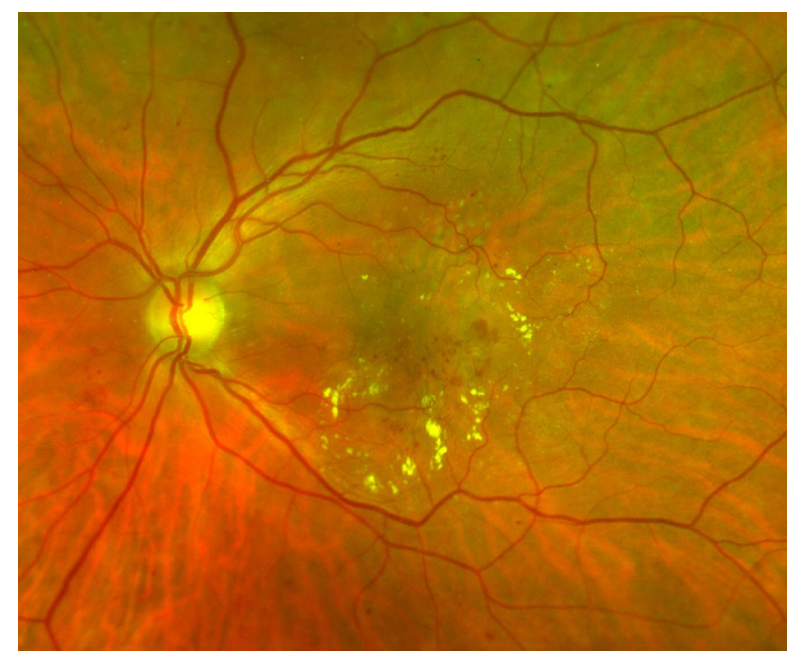

Figure 2 Wide field fundus photograph for a patient with chronic, refractory, diffuse diabetic macular edema.

Note: The patient had undergone laser photocoagulation previously. 


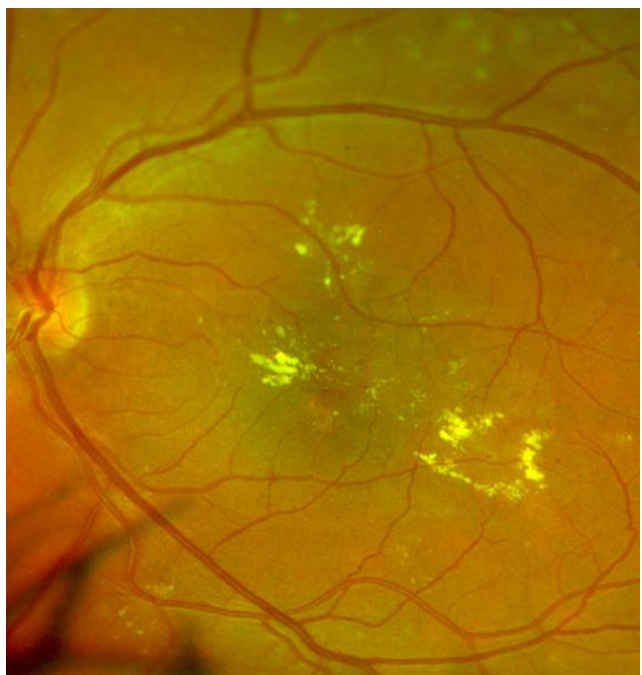

Figure 3 Refractory diabetic macular edema after six injections with ranibizumab.
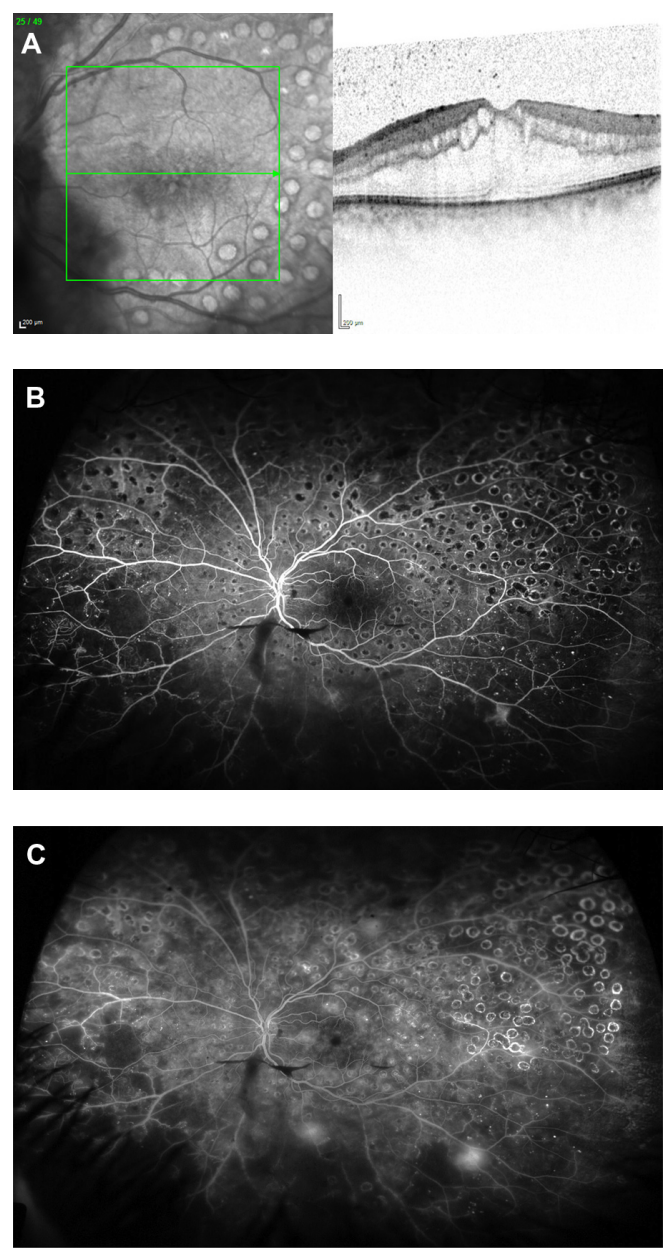

Figure 4 Patient with diffuse diabetic macular edema (A). Note the laser spots following panretinal laser photocoagulation. In the early phase of the angiogram (B) there are no clear sources of leak detectable (nonvasogenic diabetic macular edema). The periphery ( $\mathbf{B}$ and $\mathbf{C}$ ) shows extensive areas of ischemic retina which can be considered a relevant cause for vascular endothelial growth factor overexpression.

Note: In combination with anti-vascular endothelial growth factor treatment for the diabetic macular edema, these areas should be treated with laser photocoagulation. fovea or new diffuse DME. In clinical trials, the combination of intravitreal ranibizumab with prompt or deferred laser was more effective over a period of review of one year compared with prompt laser alone for the treatment of DME involving the central macula..$^{43}$ With regard to 3 -year follow-up comparing prompt or deferred laser combined with ranibizumab, visual outcomes were better in patients with deferred laser photocoagulation compared with laser treatment performed at initiation of treatment with ranibizumab. ${ }^{44}$ Additional laser photocoagulation of peripheral ischemic areas should be considered in patients receiving anti-VEGF treatment for DME (Figure 4). However, the widened spectrum of pharmacological options will help us to maintain and improve visual acuity in patients with acute or chronic DME.

\section{Disclosure}

The authors report no conflicts of interest in this work.

\section{References}

1. Harris MI. Diabetes in America: epidemiology and scope of the problem. Diabetes Care. 1998;21 Suppl 3:C11-C14.

2. Klein R, Klein BE, Moss SE, Davis MD, DeMets DL. The Wisconsin epidemiologic study of diabetic retinopathy. III. Prevalence and risk of diabetic retinopathy when age at diagnosis is 30 or more years. Arch Ophthalmol. 1984;102:527-532.

3. Klein R, Klein BEK, Moss SE, Davis MD, DeMets DL. The Wisconsin epidemiologic study of diabetic retinopathy. II. Prevalence and risk of diabetic retinopathy when age at diagnosis is less than 30 years. Arch Ophthalmol. 1984;102:520-526.

4. Early Treatment Diabetic Retinopathy Study Research Group. Early photocoagulation for diabetic retinopathy. ETDRS Report 9. Ophthalmology. 1991;98 Suppl:766-785.

5. Early Treatment Diabetic Retinopathy Study Research Group. Photocoagulation for diabetic macular edema. Arch Ophthalmol. 1985;103:1796-1806

6. Early Treatment Diabetic Retinopathy Study Research Group. Focal photocoagulation treatment of diabetic macular edema. Relationship of treatment effect to fluorescein angiographic and other retinal characteristics at baseline: ETDRS Report 19. Arch Ophthalmol. 1995;113:1144-1155.

7. Massin P, Bandello F, Garweg JG, et al. Safety and efficacy of ranibizumab in diabetic macular edema (RESOLVE study): a 12-month, randomized, controlled, double-masked, multicenter phase II study. Diabetes Care. 2010;33:2399-2405.

8. Haritoglou C, Kook D, Neubauer A, et al. Intravitreal bevacizumab (Avastin) therapy for persistent diffuse diabetic macular edema. Retina. 2006;26:999-1005.

9. Nguyen QD, Brown DM, Marcus DM, et al; RISE and RIDE Research Group. Ranibizumab for diabetic macular edema: results from 2 phase III randomized trials: RISE and RIDE. Ophthalmology. 2012;119: 789-801.

10. Frampton JE. Ranibizumab: in diabetic macular oedema. Drugs. 2012;72:509-523.

11. Audren F, Lecleire-Collet A, Erginay A, et al. Intravitreal triamcinolone acetonide for diffuse diabetic macular edema: Phase 2 trial comparing $4 \mathrm{mg}$ vs $2 \mathrm{mg}$. Am J Ophthalmol. 2006;142:794-799.

12. La Heij EC, Lundqvist IJ, Berendschot TT, Hardy E, Liem AT, Hendrikse F. Intravitreal prednisolone sodium succinate reduces diabetic macular edema without intraocular pressure rise. Am J Ophthalmol. 2007;143:176-178. 
13. Gibran SK, Cullinane A, Jungkim S, Cleary PE. Intravitreal triamcinolone for diffuse diabetic macular oedema. Eye. 2006;20:720-724.

14. Joussen AM, Poulaki V, Le ML, et al. A central role for inflammation in the pathogenesis of diabetic retinopathy. FASEB J. 2004;18: 1450-1452.

15. Kleinman ME, Baffi JZ, Ambati J. The multifactorial nature of retinal vascular disease. Ophthalmologica. 2010;224 Suppl 1:16-24.

16. Brownlee M. Glycation and diabetic complications. Diabetes. 1994;43: 836-841.

17. Frank RN. On the pathogenesis of diabetic retinopathy. Ophthalmology. 1984;91:626-634.

18. Vinores SA, Van Niel E, Swerdloff JL, Campochiaro PA. Electron microscopic immunocytochemical evidence for the mechanism of blood-retinal barrier breakdown in galactosemic rats and its association with aldose reductase expression and inhibition. Exp Eye Res. 1993;57 723-735.

19. Adamis AP, Miller JW, Bernal MT, et al. Increased vascular endothelial growth factor levels in the vitreous of eyes with proliferative diabetic retinopathy. Am J Ophthalmol. 1994;118:445-450.

20. Bhagat N, Grigorian RA, Tutela A, Zarbin MA. Diabetic macular edema: pathogenesis and treatment. Surv Ophthalmol. 2009;54:1-32.

21. Ishida S, Usui T, Yamashiro K, et al. VEGF164 is proinflammatory in the diabetic retina. Invest Ophthalmol Vis Sci. 2003;44:2155-2162.

22. Du X, Matsumura T, Edelstein D, et al. Inhibition of GAPDH activity by poly (ADP-ribose) polymerase activates three major pathways of hyperglycemic damage in endothelial cells. J Clin Invest. 2003;112: 1049-1057.

23. Brownlee M. Biochemistry and molecular cell biology of diabetic complications. Nature. 2001;414:813-820.

24. Bringmann A, Wiedemann P. Müller glial cells in retinal disease. Ophthalmologica. 2012;227:1-19.

25. Tamura H, Miyamoto K, Kiryu J, et al. Intravitreal injection of corticosteroid attenuates leukostasis and vascular leakage in experimental diabetic retina. Invest Ophthalmol Vis Sci. 2005;46:1440-1444.

26. Miyamoto K, Hiroshiba N, Tsujikawa A, Ogura Y. In vivo demonstration of increased leukocyte entrapment in retinal microcirculation of diabetic rats. Invest Ophthalmol Vis Sci. 1998;39:2190-2194.

27. Edelman JL. Differentiating intraocular glucocorticoids. Ophthalmologica. 2010;224 Suppl 1:25-30.

28. Kiernan DF, Mieler WF. The use of intraocular corticosteroids. Expert Opin Pharmacother. 2009;10:2511-2525.

29. Early Treatment Diabetic Retinopathy Study Research Group. Treatment techniques and clinical guidelines for photocoagulation of diabetic macular edema. Early Treatment Diabetic Retinopathy Study Report Number 2. Ophthalmology. 1987;94:761-774.

30. Browning DJ, Altaweel MM, Bressler NM, Bressler SB, Scott IU; Diabetic Retinopathy Clinical Research Network. Diabetic macular edema: what is focal and what is diffuse? Am J Ophthalmol. 2008;146 649-655
31. Lee CM, Olk RJ. Modified grid laser photocoagulation for diffuse diabetic macular edema. Long-term visual results. Ophthalmology. 1991;98:1594-1602.

32. Gillies MC, Simpson JM, Gaston C, et al. Five-year results of a randomized trial with open-label extension of triamcinolone acetonide for refractory diabetic macular edema. Ophthalmology. 2009;116:2182-2187.

33. Jonas JB, Degenring RF, Kreissig I, Akkoyun I, Kamppeter BA. Intraocular pressure elevation after intravitreal triamcinolone acetonide injection. Ophthalmology. 2005;112:593-598.

34. Zucchiatti I, Lattanzio R, Querques G, et al. Intravitreal dexamethasone implant in patients with persistent diabetic macular edema. Ophthalmologica. 2012;228:117-122.

35. Haller JA, Kuppermann BD, Blumenkranz MS, et al; Dexamethasone DDS Phase II Study Group. Randomized controlled trial of an intravitreous dexamethasone drug delivery system in patients with diabetic macular edema. Arch Ophthalmol. 2010;128:289-296.

36. Jonas JB, Spandau UH, Kamppeter BA, Vossmerbaeumer U, Harder B, Sauder G. Repeated intravitreal high-dosage injections of triamcinolone acetonide for diffuse diabetic macular edema. Ophthalmology. 2006;113: $800-804$.

37. Hauser D, Bukelman A, Pokroy R, et al. Intravitreal triamcinolone for diabetic macular edema: comparison of 1, 2, and $4 \mathrm{mg}$. Retina. 2008;28: 825-830.

38. Campochiaro PA, Hafiz G, Shah SM, et al; FAMOUS Study Group. Sustained ocular delivery of fluocinolone acetonide by an intravitreal insert. Ophthalmology. 2010;117:1393-1399.

39. Campochiaro PA, Nguyen QD, Hafiz G, et al; FAMOUS Study Group. Aqueous levels of fluocinolone acetonide after administration of fluocinolone acetonide inserts or fluocinolone acetonide implants. Ophthalmology. December 4, 2012. [Epub ahead of print.]

40. Campochiaro PA, Brown DM, Pearson A, et al; FAME Study Group. Sustained delivery fluocinolone acetonide vitreous inserts provide benefit for at least 3 years in patients with diabetic macular edema. Ophthalmology. 2012;119:2125-2132.

41. Campochiaro PA, Brown DM, Pearson A, et al; FAME Study Group. Long-term benefit of sustained-delivery fluocinolone acetonide vitreous inserts for diabetic macular edema. Ophthalmology. 2011;118: 626-635.

42. Pearson PA, Comstock TL, Ip M, et al. Fluocinolone acetonide intravitreal implant for diabetic macular edema: a 3-year multicenter, randomized, controlled clinical trial. Ophthalmology. 2011;118:1580-1587.

43. Elman MJ, Aiello LP, Beck RW, et al; Diabetic Retinopathy Clinical Research Network. Randomized trial evaluating ranibizumab plus prompt or deferred laser or triamcinolone plus prompt laser for diabetic macular edema. Ophthalmology. 2010;117:1064-1077.

44. Elman MJ, Qin H, Aiello LP, et al; Diabetic Retinopathy Clinical Research Network. Intravitreal ranibizumab for diabetic macular edema with prompt versus deferred laser treatment: three-year randomized trial results. Ophthalmology. 2012;119:2312-2318.
Clinical Ophthalmology

\section{Publish your work in this journal}

Clinical Ophthalmology is an international, peer-reviewed journal covering all subspecialties within ophthalmology. Key topics include: Optometry; Visual science; Pharmacology and drug therapy in eye diseases; Basic Sciences; Primary and Secondary eye care; Patient Safety and Quality of Care Improvements. This journal is indexed on Submit your manuscript here: http://www.dovepress.com/clinical-ophthalmology-journal

\section{Dovepress}

PubMed Central and CAS, and is the official journal of The Society of Clinical Ophthalmology (SCO). The manuscript management system is completely online and includes a very quick and fair peer-review system, which is all easy to use. Visit http://www.dovepress.com/ testimonials.php to read real quotes from published authors. 